\section{Vitamins and intelligence tests}

SIR - I write in an effort to counteract the negative impression about the possible value for children of a daily vitaminmineral supplement given by three articles in a recent issue of Nature ${ }^{1-3}$ discussing a paper by Schoenthaler et al. ${ }^{4}$. I was not one of the authors of this paper, but I was mentioned in one of the articles $^{2}$ and I made a statement about the matter for the BBC programme broadcast on 27 February 1991.

I had acted for the Dietary Research Foundation as an adviser and critic of the Schoenthaler study. Some of my points of criticism have been reported in the Blinkhorn article ${ }^{3}$. It is my opinion that, although the Schoenthaler study is not by itself convincing, it adds to the earlier evidence that supplementary vitamins and minerals improve, for many children, their performance on psychological tests, perhaps by improving their alertness and awareness.

The earlier study that made the greatest impression on me was that of Kubala and $\mathrm{Katz}^{5}$. These investigators first measured the amount of vitamin $C$ in the blood plasma of school children in Texas. Half of the children were low in this vitamin, less than $1.10 \mathrm{mg} \mathrm{dl}^{-1}$, and half were high, with more than this amount. They then selected 72 pairs, matched for socio-economic status (family income, education of father and mother), for further study. The average measured IQ of the low vitamin $\mathrm{C}$ group was 4.51 units lower than that of the high vitamin $\mathrm{C}$ group. After they had received a supplement of $90 \mathrm{mg}$ (one glass of orange juice) per day for six months the tests were repeated: the low group, for which the vitamin $\mathrm{C}$ level had risen into the high range, had an average increase in measured IQ of 3.54 IQ units, whereas the average increase for the other group was only 0.02 . The study was then repeated with 32 matched pairs, over 18 months with four IQ measurements. The measured IQ increased steadily by 3.6 units as the average plasma vitamin $C$ level increased from 1.03 to $1.55 \mathrm{mg} \mathrm{dl}^{-1}$.

There is also some evidence that an increased intake of nutrients other than vitamin $C$ contributes to this effect ${ }^{6-8}$.

In the Schoenthaler study, the subjects were not divided into well-nourished and poorly nourished groups, and fewer than half may have been poorly nourished. Most British children are in the poorlynourished group, as determined by the plasma levels of vitimans. I am confident that the daily intake of a vitamin-mineral supplement would on the average improve their performance in intelligence tests and also improve their general health. The medical authorities have been astonishingly reluctant to recognize the value of vitamin-mineral dietary supplements, which at low cost can improve every person's health.

One supplement, called Vitachieve, is mentioned in Nature ${ }^{2}$. This supplement does not differ much in composition from other vitamin-mineral supplements, and I doubt whether it is more effective than others. My advice is to buy the cheapest supplement, after checking the amounts of the nutrients that you would get for your money. Unless you buy a high-priced product, the money would be well spent.

of Science and Medicine,

440 Page Mill Road,

Palo Alto, California 94306, USA

1. Nature 350, 2-3 (1991).

2. Aldhous, P. Nature 350, 5 (1991)

3. Blinkhorn, S. Nature 350, 13 (1991).

Schoenthaler, S. J. et al. Personality and individual Differences 12, 329-366 (1991).

5. Kubala, A. L. \& Katz, M. M. J. genetic Psychol. 96, 343-352 (1960)

6. Pauling, L. Vitamin $C$ and the Common Cold (Freeman San Francisco, 1970)

7. Pauling, L. Vitamin C, the Common Cold, and the Filu (Freeman, San Francisco, 1976).

8. Pauling, L. How to Live Longer and Feel Better (Freeman, New York, 1986)

\section{Powdered milk} breast milk substitutes in developing countries has been obfuscated by a lack of information about what exactly the offending practice is, and your leading article on the appeal by the Church of England's General Synod for a boycott of Nestlé's coffee in this country (Nature 352,$266 ; 1991$ ) only clouds the matter further. It misrepresents both the Synod's motives for advocating the boycott and the underlying facts of the matter by parading loose assumption and speculation as fact. It is clear from reports of the Synod debate (Church Times 19 July 1991) that the churchmen consider the issue as far from simple, and that all the confounding factors you mention such as the risk of AIDS transfer by breast feeding were taken into consideration before the vote was taken. It is also important to realize that the World Health Organization (WHO) has been condemning Nestlé's activitities in this area for years, though sadly to no avail, which is why your assertion that the WHO's demand for the advertising of the benefits of mother's milk "in principle, should ensure that manufacturers will no longer play on the credulity of unsophisticated mothers in developing countries" carries little conviction.

The objection is not simply to over-

\section{Linus Pauling Institute}

SIR - The issue of Nestlé's marketing of selling the benefits of powdered milk formula in poor countries as you state, but to the insidious practice of distributing free milk to maternity wards in order to create a market for the product among nursing mothers by the time they leave hospital, despite the risks inherent in bottle-feeding where clean water is scarce and infection rife. It is this exploitation of the health and lives of the poor for financial gain that is under criticism, and if Nestle is indeed guilty it is surely appropriate for Synod to register its disapproval by discouraging trade with the offending organization.

It is easy to vilify Nestle (and the other multinational companies with similar marketing interests in developing countries), in the light of these rumours, but it would be wrong to do so without availing ourselves of the whole story. For similar reasons I think you are unjustified in assuming the action taken by the Church of England's governing body to have been hasty and unthinking. I hope the publicity gained from Synod's decision will at least prompt a longoverdue statement on this issue from Nestlé before too many wild conclusions are drawn from its present reticence.

JAMES VICKERS

\section{Department of Medicine,} University Hospital,

Queen's Medical Centre,

Nottingham NG7 2UH, UK

Sir - Sadly, the issue raised by "the British Anglican plan to boycott Nestlé coffee" is not as simple as you think. This laboratory is involved in human milk research 1,2 . Human milk substitutes in any form are less than ideal infant food, but in powdered form the product can be dangerous - and not only because of problems resulting from mixing the powder with poor-quality water and non-sterile conditions. It is difficult for mothers to measure the correct concentration. If there is too little powder, the infant does not get needed nutrients, but if there is too much (and by a narrow margin), there is the real possibility of stressing the infant's metabolic machinery ${ }^{3}$

Why has this battle been left to the Anglican church? Where are the regulatory agencies of the industrialized countries? Where are the Food and Drug Administration and the US Department of Agriculture? Women in the United States need to be informed and protected. They are really "the less fortunate counterparts" in this instance.

M. F. GoldFARB

Anatek-EP, 17 Bishop Street,

Portland, Maine 04103, USA

1. Goldfarb, M. F. \& Savadove, M. S. Electrophoresis 10, 67-70 (1989)

2. Goldfarb, M. F. \& Savadove, M. S. J. Pediat. Gastroent. Nutr. 12, 142-143 (1991)

3. Raina, N. C. R. Pediatrics 75, 136-141 (1985) 